\title{
How affluence harms the environment in Europe
}

\section{Increased use of fertilizer is not an option in crowded lands where it is already a problem.}

Sir - Stephen Budiansky has discussed in Correspondence ${ }^{1}$ how, in the United States, affluence could be good for the environment. He argued that although the US population grew by $90 \%$ and the real per capita disposable personal income grew by 177\% between 1945 and 1997, the per capita area used for food production, urban areas and other land uses remained unchanged, or even declined.

The per capita land use for food production in the United States (1.69 ha) is slightly lower than in developing countries (sub-Saharan Africa is on average $2 \mathrm{ha}$ ), whereas food production is several magnitudes higher. Budiansky cites higher use of fertilizer as the main factor accounting for the higher yields per hectare. Two new reports ${ }^{2,3}$ give us the opportunity to translate this view into a western European perspective.

Flanders in Belgium is among the richest and most developed regions in the world. Between 1990 and 2000 the population grew by $3 \%$, while the real per capita disposable personal income grew by $60 \%$. In contrast to the United States, the areas for food production and habitation have grown by $5.5 \%$ and $24 \%$, respectively, over the past ten years. Compared with the United States (agriculture 1.69 ha; urban and other land use $0.13 \mathrm{ha}$ ), land use per capita in Flanders is very low (agriculture 0.14 ha; urban and other land use $0.06 \mathrm{ha}$ ). However, because of the high population density, there is only 0.23 ha per capita of Flemish territory available ( 2.8 ha in the United States). Therefore, about $62 \%$ of Flanders is allotted to food production, while $27 \%$ is covered by urban areas and other land use, leaving only about $11 \%$ for nature (about $30 \%$ in the United States).

Budiansky does not discuss the environmental impact that goes beyond land use (see ref. 4 for one example). Agriculture is extremely intensive in Flanders, emitting Europe's highest levels of nutrients into the environment. The OECD nutrient balance database for 2001 (see www.oecd.org) shows that during the past decade the nitrogen surplus (from manure) was between $177 \mathrm{~kg}$ and $203 \mathrm{~kg}$ per ha of total agricultural land. The critical load for grasslands in nature reserves and natural grasslands in agricultural areas was exceeded in all sampled points ${ }^{2}$. As a consequence, vegetation of nutrient-rich environments gradually replaced that of nutrient-poor environments throughout Flanders ${ }^{3}$. Overfertilization is causing species extinction; for example it is one of the main reasons why nearly a third of the area's butterfly species have been wiped out during the past century ${ }^{5}$. The rate of extinctions is speeding up, with half the remaining species expected to die out during this century.

Although present policy aims to tackle the problem at the source by limiting nutrient emissions, atmospheric nitrogen deposition is barely decreasing, and nutrients will continue to accumulate for some time to come ${ }^{3}$.

Luc De Bruyn ${ }^{\star}$, Jan Scheirs $\dagger$, Hans Van Gossum $\dagger$

*Institute of Nature Conservation, Kliniekstraat 25, 1070 Brussels, Belgium

$\dagger$ Department of Biology, University of Antwerp (RUCA), Groenenborgerlaan 171, 2020 Antwerp, Belgium

\footnotetext{
1. Budiansky, S. Nature 416, 581 (2002).

2. Van Steertegem, M. MIRA-T 2001 (VMM, Garant, 2001)

3. Kuijken, E., et al. Nature Report 2001 in a Nutshell (Institute of

Nature Conservation, Brussels, 2002).

4. Reay, D. Nature 417, 15 (2002).

5. Maes, D., Van Dyck, H. Biol. Conserv. 99, 263-276 (2001).
}

\section{0 no: opossums are not at risk in Tasmania}

Sir - In your welcome News story highlighting the severe threat to Tasmanian wildlife by the introduction of the red fox from the Australian mainland ${ }^{1}$, your claim that farmers and foresters use sodium monofluoroacetate (1080) to control opossums and wallabies that graze on crops and native trees in Tasmania is not correct.

First, opossums do not occur in any part of Australasia, including Tasmania; they are found only in North and South America, where they are carnivorous marsupials (polyprotodonts). Possums occur in Australia and are herbivorous marsupials (diprotodonts). The perception that opossums live in Australia dates back to the Cook and Banks voyage of 1770, when an arboreal marsupial seen in Queensland was described as being similar to the Brazilian opossum.

It is more than 20 years since the Australian Mammal Society adopted a list of common names for Australian mammals. This included a recommendation that the 'o' be dropped from the name of these Australian arboreal herbivores ${ }^{2}$.
Second, the possums and wallabies that are the target of 1080 poison graze grass but browse trees. Browsers feed mostly on twigs and leaves from trees and shrubs, such as the eucalypt seedlings often planted by foresters and farmers in Tasmania, whereas grazers eat mostly grasses and herbs ${ }^{3}$.

The main point of your story — that the red fox severely threatens Tasmania's wild life, and that effective action is required to counteract this now - is undoubtedly true. Your News story states that up to 77 known species are under threat; we can be sure that future generations will look back to see how well their politicians and biologists served us at this time.

Thomas L. Montague*,

Andrew T. D. Bennett $\dagger$

${ }^{*}$ Roe Koh \& Associates P/L, PO Box 789,

Mornington, Victoria 3931, Australia

$\dagger$ School of Biological Sciences, University of Bristol, Bristol BS8 1UG, UK

1. Dennis, C. Nature 416,357 (2002).

2. Kerle, J. A. Possums (UNSW Press, Sydney, 2001).

3. Strahan, R. The Complete Book of Australian Mammals (Angus \& Robertson, Sydney, 1988).

Possums were correctly identified by the author of the original story. The error was inadvertently introduced during editing - Editor, Correspondence

\section{What can Venter teach students about ethics?}

Sir — In your Opinion article "Selling science to the young" (Nature 417, 1;2002) outlining what should be done to attract young people back to science, you remark that "many graduates do turn their science degrees into decent financial as well as spiritual reward".

I was shocked to read, on the very next page, the News report (Nature 417, 3; 2002) about Craig Venter, who, after making a fortune, now, as your headline puts it, "lays foundations for fresh career as ethical philanthropist". In his own words, he plans to "spend some time examining my own genetic code".

What kind of image of science does this create? Let's hope that there still exists a pool of young scientists with a passion and vocation for doing basic research, otherwise cash-strapped universities and government research organizations will soon run out of personnel. It's a sad day for science if the criterion of success is measured in purely financial terms. Rod Ceredig Institut National Scientifique et de la Recherche Medicale, 17 rue des Martyrs, F-38054 Grenoble, France 